\title{
Medicinal mishap
}

\section{Fatal azathioprine toxicity}

\section{Case}

A 59-year-old female underwent a renal transplant in early 2015. Her initial immunosuppression regimen was mycophenolate mofetil, prednisolone and tacrolimus. The post-transplant recovery was complicated by chronic diarrhoea. This was related to mycophenolate and occurred with both the mofetil and the sodium salts.

In January 2016, while the patient was overseas, her diarrhoea worsened. She was admitted to hospital where mycophenolate sodium was stopped and azathioprine was started.

When assessed back in Australia, one month after starting azathioprine, the patient was found to have severe pancytopenia and she was admitted to hospital. The azathioprine was stopped, but the pancytopenia persisted despite three weeks of treatment with filgrastim and blood products. It was complicated by febrile neutropenia and polymicrobial sepsis. The patient died one month after admission from multiorgan failure secondary to bone marrow failure.

\section{Comment}

Azathioprine, a prodrug of mercaptopurine, is a purine antimetabolite which suppresses the immune system. In addition to preventing the rejection of organ transplants, it can be used to manage a range of autoimmune and inflammatory conditions such as inflammatory bowel disease and systemic lupus erythematosus.

The enzyme thiopurine methyltransferase (TPMT) is important for converting azathioprine and mercaptopurine into inactive metabolites. This reduces the consequent risk of myelosuppression. In 0.3-0.6\% of Caucasians there are genetic polymorphisms that lead to markedly reduced TPMT activity.' During her final admission our patient was found to have a genetic polymorphism, which resulted in low TPMT activity. This made her extremely sensitive to the myelosuppressive effects of azathioprine.
The role of genetic testing is uncertain. Pathology laboratories often report intermediate-activity genetic polymorphisms, however the clinical implications of this result are unclear. TPMT activity can also be quantified by directly testing the enzyme's activity (often described as a TPMT phenotype). While this method should capture all patients with low TPMT activity, the result is subject to significant intraindividual variability. ${ }^{2}$ Either method of testing is practically effective in detecting patients with low enzyme activity. An alternative approach to the patient taking azathioprine is to frequently monitor the full blood count, looking for the onset of neutropenia.

\section{Recommendations}

This case highlights that low TPMT activity, although uncommon, can have fatal consequences, particularly if there are inadequate blood counts in patients taking azathioprine. Routine testing may be useful in predicting an individual patient's risk of myelosuppression, as well as adjusting dosing. ${ }^{3}$ It is easy to incorporate into standard practice, and is likely to have a favourable cost-benefit profile. ${ }^{4}$

We recommend that TPMT testing should be strongly considered before starting azathioprine. Azathioprine use can usually be anticipated so testing should be done before the patient starts the drug.

TPMT testing identifies a large proportion, but not all, of patients at risk of severe myelosuppression. Patients taking azathioprine should therefore have regular full blood counts, particularly during the first three months of therapy (at least weekly).

We would like to acknowledge the patient's family for permitting use of this case.

David Liew is attending Editorial Executive Committee meetings as the clinical pharmacology registrar for Australian Prescriber in 2017.

\section{REFERENCES}

1. Australian medicines handbook. Adelaide: Australian Medicines Handbook; 2017. https://amhonline.amh.net.au [cited 2017 May 1]

2. Lennard L, Cartwright CS, Wade R, Richards SM, Vora A. Thiopurine methyltransferase genotype-phenotype discordance and thiopurine active metabolite formation in childhood acute lymphoblastic leukaemia. Br J Clin Pharmacol 2013:76:125-36. http://dx.doi.org/10.1111/bcp.12066
3. Relling MV, Gardner EE, Sandborn WJ, Schmiegelow K, Pui CH, Yee SW, et al. Clinical Pharmacogenetics Implementation Consortium guidelines for thiopurine methyltransferase genotype and thiopurine dosing. Clin Pharmacol Ther 2011;89:387-91. http://dx.doi.org/10.1038/clpt.2010.320

4. Ford LT, Berg JD. Thiopurine S-methyltransferase (TPMT) assessment prior to starting thiopurine drug treatment; a pharmacogenomic test whose time has come. J Clin Pathol 2010;63:288-95. http://dx.doi.org/10.1136/jcp.2009.069252

\section{David Liew}

Clinical pharmacology registrar and Rheumatology fellow

\section{Claire Keith}

Medicines information

pharmacist

\section{Jane Booth}

Senior medicines

information pharmacist

\section{Dhineli Perera}

Clinical pharmacist

Austin Health

Melbourne

Aust Prescr 2017:40:109

http://dx.doi.org/10.18773/ austprescr.2017.035 